\title{
REVIEW
}

\section{The unfolding drama of flower development: recent results from genetic and molecular analyses}

\author{
Hong Ma \\ Cold Spring Harbor Laboratory, Cold Spring Harbor, New York 11724-2212 USA
}

There has been an explosion of information about flower development recently, largely because of genetic and molecular studies in Arabidopsis thaliana and Antirrhinum majus. A number of homeotic genes have been identified that regulate flower development, and models have been proposed for the specification of meristem and floral organ identities. Molecular cloning of many of these genes has allowed the testing of specific predictions of the models but also has led to modifications of a floral organ identity model. Furthermore, several of the floral genes contain a conserved region, the MADS box, which encodes a domain with striking sequence similarity with known transcription factors from human and yeast. Additional MADS box genes have been isolated from several plants; these genes are likely to play important regulatory roles during flower development. The genetic and molecular studies have uncovered many of the components of a complex network of regulatory proteins that directs flower development. Further characterization of these and other yet to be discovered components promises to contribute a great deal to our understanding of the mechanisms controlling flower development.

Flowering plants, like other land plants, have vegetative organs such as roots, stems, and leaves, which absorb nutrients and water from the soil, transport them to other parts of the plant, and synthesize organic compounds using the sun's energy. In addition, flowering plants produce elaborate reproductive structures, the flowers, which, following fertilization, become fruits and bear seeds. From the seasoned gardener to the casual observer, from the naturalist to the florist shopper, people have always been fascinated by the enormous variety of flowers, ranging from $2 \mathrm{~mm}$ to $>10 \mathrm{~cm}$ in length, covering the whole visual spectrum with their colors, and differing in the arrangement of flowers and the symmetry within a flower. How do flowers develop? What genes regulate this complex process? In recent years, rapid advances have been made in addressing these questions, largely as a result of genetic and molecular studies in two distantly related flowering plants, Arabidopsis thaliana, a relative of cauliflower and cabbage, and the snapdragon, Antirrhinum majus.

Postembryonic plant development is repetitive, be- cause of the reiterative nature of the morphogenesis initiated from the meristems, which are groups of undifferentiated progenitor cells. The meristem at the apex of the plant (or the tip of a stem) is called the apical meristem. While the cells at the very summit of the domeshaped apical meristem divide and maintain the meristem, the cells at the periphery of the apical meristem divide to give rise to additional meristems (e.g., of branches) or organ primordia, which are groups of cells with specified fates and which develop into different organs, such as leaves. The cells just below the apical meristem divide and differentiate to form the stem itself. Many plants, such as trees, have a recognizable dominant stem (trunk), with the primary apical meristem, and additional branches, each with a meristem at the tip. Other plants lack an obvious dominant stem and a primary meristem, and have a bushy morphology. In Arabidopsis, the vegetative apical meristem produces leaves arranged in a spiral arrangement with very short distances between successive leaves, forming a rosette (Fig.1a). In contrast, the Antirrhinum vegetative apical meristem produces pairs of leaves opposite to each other, and each pair is at right angle with the previous pair (Fig. $1 b$; Coen and Meyerowitz 1991).

Flower development requires several steps (Meyerowitz et al. 1991). The first step is floral induction, which establishes a reproductive meristem(s). The reproductive meristem is often called an inflorescence meristem because it gives rise to a series of flowers, called an inflorescence. The number of flowers in an inflorescence varies between species and ranges from several (determinate inflorescence) to indefinite (indeterminate inflorescence). Both Arabidopsis and Antirrhinum have indeterminate inflorescences (Fig. 1a,b). The second step is the formation of a floral meristem (Fig. 1c), which is homologous to a branch meristem, for a flower can be regarded as a very short stem with specialized organs. In some plants, floral induction results in the formation of a floral meristem directly, and a single flower develops at the end of a stem. In Arabidopsis, the primary inflorescence meristem gives rise to, in a spiral, first a small number of cauline leaf primordia (Fig. 1a), each with an adjacent secondary inflorescence meristem, and then a large (in- 
a
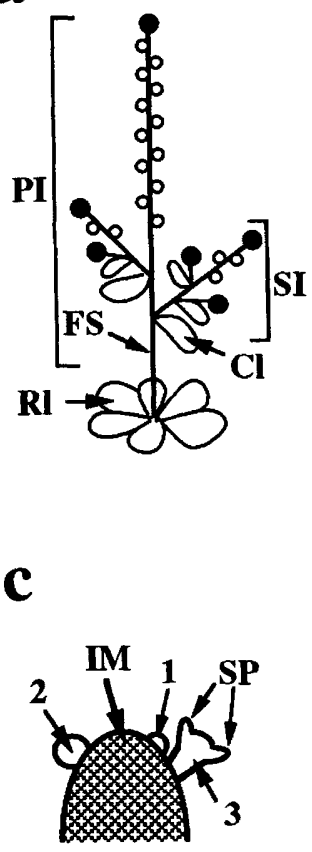

b

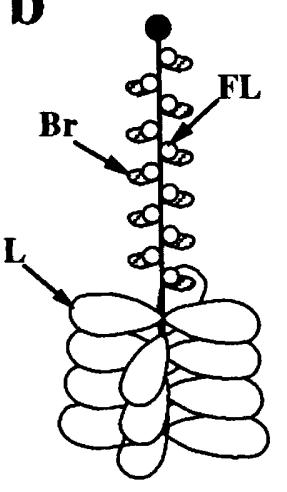

d

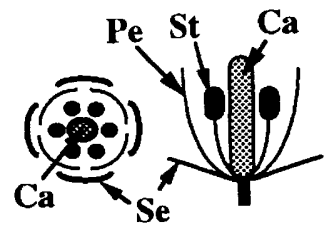

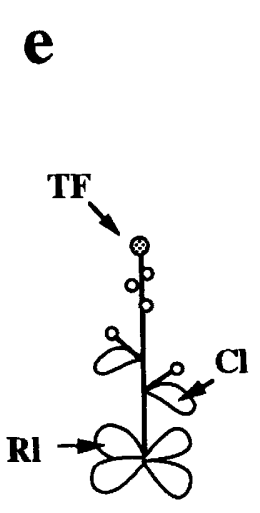
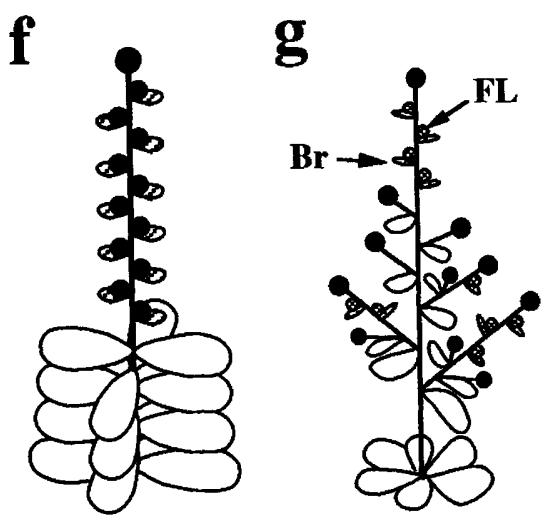

h

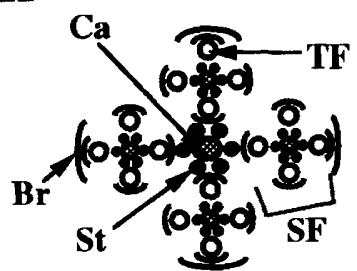

i

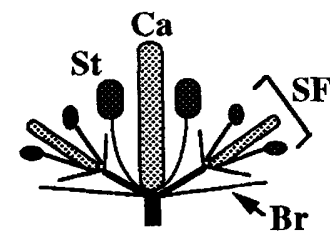

Figure 1. Schematic representation of wild-type $(a-d)$ and mutant $(e-i)$ Arabidopsis and Antirrhinum plants and flowers. $(a)$ A wild-type Arabidopsis plant, showing rosette leaves (Rl), floral stem (FS), primary inflorescence (PI), and secondary inflorescence (SI), which are subtended by cauline leaves $(\mathrm{Cl})$. The leaves and flowers arise in a spiral arrangement. Flowers are represented by open circles, and inflorescences are represented by solid circles. (b) A wild-type Antirrhinum plant, showing leaves (L) and flowers (FL), subtended by bracts $(\mathrm{Br}) .(\mathrm{c})$ The apex of a wild-type Arabidopsis inflorescence, with inflorescence meristem (IM), and floral primordia. The period from floral meristem initiation to floral bud opening has been divided into 12 stages on the basis of morphological landmarks (Smyth et al. 1990). The first three stages are as follows: (1) Floral meristem appears as a buttress on the flank of inflorescence meristem; (2) floral meristem becomes globular shaped; and |3| sepal primordia (SP) arise on the flank of the floral primordium. (d) Top (left) and side (right) views of a wild-type Arabidopsis flower, showing four whorls: four sepals (Se), four petals $(\mathrm{Pe})$, six stamens $(\mathrm{St})$, and an ovary with two united carpels (Ca). (e) An Arabidopsis tfl1 plant, showing reduced number of rosette leaves, and flowers instead of secondary inflorescences are subtended by cauline leaves. At the apex, a terminal flower (TF) is formed. (f) An Antirrhinum flo plant. Flowers are converted to secondary inflorescences, which produce no flowers. The squa plants are similar, except that the secondary inflorescences do produce some flowers. $(g)$ An Arabidopsis lfy plant. True inflorescences are shown as solid circles, and abnormal flowers with inflorescence properties are shown as hatched circles (FL). Note that the lfy plant has more secondary inflorescences than wild type, and that the abnormal flowers are subtended by bracts. Top (h) and side (i) views of an ap1 flower: sepals are converted to bracts, and secondary flowers (SF) arise interior to the bracts, with tertiary flowers (TF) interior to the bracts of secondary flowers; petals are absent, whereas stamens and carpels are normal.

definite) number of floral meristems (Fig. 1a,c). In contrast, the Antirrhinum inflorescence meristem produces, also in a spiral, small leaf-like bracts, each with an adjacent floral meristem (Fig. 1b), but no secondary inflorescences. The third step is the formation of floral organ primordia, which are organized groups of cells occupying different positions within the floral meristem. After the organ primordia are formed, the identities of the organs are determined to specify the fate of cells within these organs. Finally, during floral organ development, specific programs are executed leading to organs with characteristic final forms and functions. Arabidopsis flowers have four concentric whorls (rings) of organs, and from the periphery to the center they are four green sepals (protective and most leaf-like), four white petals (in many plants, colorful and attractive to insects), six pollen-producing stamens (male), and an ovary (female) consisting of two united carpels (Fig. 1d). Although Antirrhinum flowers also have the same four whorls of organs, the flowers have bilateral symmetry and are much larger than those of Arabidopsis. In addition, the petals of $A n$ tirrhinum flowers are fused in the lower half to form a tube.

Despite the apparent differences between Arabidopsis and Antirrhinum, flower development in these plants is regulated by remarkably similar genes (Schwarz-Sommer et al. 1990; Coen 1991, 1992; Coen and Meyerowitz 1991; Weigel and Meyerowitz 1993b). Many of the mutant phenotypes have been observed in plants that are evolutionarily divergent, suggesting that what is true for Arabidopsis and Antirrhinum is likely to be conserved in other plants even though a tremendous amount of variation exists among flowers of different plants (Meyerowitz et al. 1989). Furthermore, homologs of the Ara- 
bidopsis and Antirrhinum floral genes have been identified in many other plants, including the monocot maize (e.g., Pnueli et al. 1991; Mandel et al. 1992a; Kempin et al. 1993; Schmidt et al. 1993; van der Krol et al. 1993). This review summarizes recent genetic studies in Arabidopsis and Antirrhinum, and emphasizes recent results from molecular analyses in these two plants, as well as some studies from a few other plants. These results indicate that a complex network of regulators controls the formation of the inflorescence meristem and its transition to the floral meristem, the initiation of floral organ primordia, and the floral organ identities. The first three sections present brief descriptions of mutant phenotypes. These are followed by discussions of genetic interactions based on double and triple mutant studies and on molecular analyses using cloned genes. Finally, the biochemical nature of many of the gene products and possible regulatory mechanisms is discussed. Because of limited space, morphological and physiological studies in other plants are not discussed here, nor are there detailed accounts of earlier genetic studies, for which the reader is referred to several excellent reviews (Meyerowitz et al. 1989, 1991; Schwarz-Sommer et al. 1990; Coen 1991; Coen and Meyerowitz 1991). Other recent reviews offer different perspectives and emphasis (Coen 1992; Coen and Carpenter 1992; Jack et al. 1993; Weigel and Meyerowitz 1993b).

\section{Prelude: floral induction}

Floral induction is regulated by developmental and environmental factors (Bernier et al. 1993). In Arabidopsis, it seems that reproductive development is a default pathway and that normal vegetative growth occurs when the reproductive program is delayed as a result of inhibition. This inhibition is removed only when developmental and environmental signals are present, as indicated by genetic studies. The recessive mutant emf produces a single flower upon seed germination, without any vegetative growth (Sung et al. 1992), suggesting that EMF is required for the inhibition of reproductive growth. Mutations in another gene, TFL1, cause a reduction of the number of vegetative (rosette) leaves, and an earlier than normal appearance of inflorescence (Shannon and Meeks-Wagner 1991; Schultz and Haughn 1993). This suggests that the TFL1 gene may enhance the inhibition of reproductive growth before the appropriate developmental stage, although this could be related to a negative role TFL1 has in floral meristem initiation (Fig. 1e; also see below in Act 1).

Flower induction in Arabidopsis is influenced by the length of daylight and temperature (Bernier et al. 1993). Long days (14-16 hr light/8-10 hr dark) accelerate flowering as compared with short days $(8-10 \mathrm{hr}$ light/14-16 $\mathrm{hr}$ dark); furthermore, cold treatment promotes early flowering (Bernier et al. 1993). A group of mutants, known as late-flowering mutants, have been found to change the regulation of flowering by environmental conditions (Koornneef et al. 1991; Araki and Komeda 1993; Lee et al. 1993|. Both long-day conditions and cold reduce the delay of flowering in some, but not all, of the late flowering mutants. Biochemical studies (Burn et al. 1993) indicate that cold treatment causes demethylation of DNA and that the DNA demethylation may be involved in reducing the delay of flowering. It will be possible in the near future to learn the molecular mechanisms of the late flowering gene functions, for efforts have begun in earnest to isolate and characterize the late flowering genes at the molecular level (e.g., Putterill et al. 1993).

\section{Act 1: floral meristem initiation}

The characterization of Arabidopsis and Antirrhinum mutants have identified several genes that control floral meristem initiation (Table 1). The phenotypes of several mutants (leafy and apetala1 in Arabidopsis, and floricaula and squamosa in Antirrhinum; see below) suggest that the corresponding wild-type genes promote the transition from inflorescence to floral meristems /Coen et al. 1990; Irish and Sussex 1990; Schultz and Haughn 1991; Huala and Sussex 1992; Huijser et al. 1992; Mandel et al. 1992b; Weigel et al. 1992; Bowman et al. 1993). In the Antirrhinum floricaula (flo) mutants (Fig. If), floral meristems fail to form; secondary inflorescence meristems form instead. Similarly, in the Arabidopsis leafy (Ify) mutants (Fig. $1 \mathrm{~g}$ ), early flowers are replaced by secondary inflorescences. Although late Ify flowers do form, they are abnormal and subtended by bracts (not present in the wild type). These flowers resemble secondary inflorescences in several ways: (1) The outer organs resemble cauline leaves, with occasional secondary flowers; (2) the distance between whorls is extended; and (3) the organ arrangement is partially spiral. The Arabidopsis $A P$ ETALA1 (AP1) and the Antirrhinum SQUAMOSA (SQUA) genes also act positively in the inflorescence-toflower transition. The flowers of the ap1-1 mutant (Fig. $\mathrm{lh}, \mathrm{i})$ contain secondary flowers interior to the first whorl organs and tertiary flowers interior to the first whorl organs of the secondary flowers, making each primary flower a miniature inflorescence /although the arrangement is whorled instead of spiral). Likewise, squa mutants produce inflorescence-like shoots instead of flowers, indicating that the mutants are deficient in floral meristem initiation; however, these secondary shoots do eventually produce some flowers.

The Antirrhinum FLO and SQUA, and the Arabidopsis $L F Y$ and $A P 1$ genes, have been isolated (Coen et al. 1990; Huijser et al. 1992; Mandel et al. 1992b; Weigel et al. 1992). FLO and $L F Y$ encode homologous proteins with proline-rich and acidic regions, both characteristics of transcription factors. The idea that LFY is a transcriptional regulator is further supported by its localization to the nucleus (Weigel and Meyerowitz 1993a). The AP1 and the SQUA genes were isolated independently and found homologous to each other; their gene products are members of a family with similarity to transcription factors (see below in The Players). All four genes are expressed in very early floral meristems, consistent with their roles in determining meristem identity /Coen et al. 
Table 1. Arabidopsis and Antirrhinum floral genes

\begin{tabular}{|c|c|c|c|c|}
\hline \multicolumn{2}{|c|}{ Genes $^{a}$} & \multirow{2}{*}{$\begin{array}{l}\text { Gene } \\
\text { products }^{b}\end{array}$} & \multirow{2}{*}{$\begin{array}{l}\text { Single mutant phenotypes } \\
\text { or expression patterns }\end{array}$} & \multirow[b]{2}{*}{ References $^{c}$} \\
\hline Arabidopsis & Antirrhinum & & & \\
\hline \multicolumn{5}{|c|}{ Genes regulating transition from vegetative to reproductive development } \\
\hline $\begin{array}{l}\text { Late flowering } \\
\text { genes }\end{array}$ & $?$ & $?$ & delayed flowering & 1 \\
\hline EMF & $?$ & $?$ & flowering without vegetative growth & 2 \\
\hline TFL1 & $?$ & $?$ & early flowering & 3 \\
\hline \multicolumn{5}{|c|}{ Genes controlling floral meristem initiation and size } \\
\hline TFL1 & $?$ & $?$ & inflorescence to floral meristems & 3 \\
\hline$?$ & $C E N$ & & terminal flower with radial symmetry & 4 \\
\hline$L F Y$ & FLO & Transcription factor? & flowers to (lfy, partial) inflorescences & 4,5 \\
\hline$A P 1$ & $S Q U A^{\mathrm{d}}$ & MADS domain & $\begin{array}{l}\text { ap1, flowers interior of first whorl organs } \\
\text { squa, inflorescence replacing flowers }\end{array}$ & 6,7 \\
\hline$C A L$ & $?$ & $?$ & enhancement of ap1 phenotype & 7 \\
\hline$C L V 1$ & $?$ & $?$ & large meristem, more floral organs & 8,9 \\
\hline$C L V 2$ & $?$ & $?$ & more carpels & 9 \\
\hline \multicolumn{5}{|c|}{ Genes specifying floral organ identity } \\
\hline$A P 1$ & $S Q U A^{\mathrm{d}}$ & MADS domain & $\begin{array}{l}\text { ap1, sepals to bracts, abnormal petals } \\
\text { squa, abnormal organs in outer whorls }\end{array}$ & 6,7 \\
\hline$A P 2$ & $?$ & $?$ & sepals to carpels, petals to stamens & $4,10,12$ \\
\hline$A G^{\mathrm{d}}$ & PLENA & MADS domain & stamens to petals, carpels to flowers & $4,10,11$ \\
\hline$A P 3$ & $D E F A^{\mathrm{d}}$ & MADS domain & petals to sepals, stamens to carpels & $4,10,13$ \\
\hline$P I$ & $G L O^{\mathrm{d}}$ & MADS domain & similar to ap3 and $\operatorname{def} A$ & $4,10,13$ \\
\hline$?$ & SEP & $?$ & similar to $\operatorname{def} A$ & 4 \\
\hline SUP & $?$ & $?$ & more stamens, reduction of carpels & 4,14 \\
\hline \multicolumn{5}{|c|}{ Genes controlling floral symmetry } \\
\hline- & CYC & $?$ & bilateral to radial symmetry & 4 \\
\hline \multicolumn{5}{|c|}{ Genes isolated by sequence similarity to $A G$} \\
\hline$A G L 1$ & & MADS domain & expressed in carpels & 15 \\
\hline$A G L 2$ & & MADS domain & expressed in flowers & 15 \\
\hline$A G L 4$ & & MADS domain & expressed in flowers & 15 \\
\hline$A G L 5$ & & MADS domain & expressed in flowers & 15 \\
\hline AGL6 & & MADS domain & expressed in flowers & 15 \\
\hline
\end{tabular}

${ }^{a}$ Classification is based on single mutant phenotypes. The homologs are listed side by side.

${ }^{\mathrm{b}}$ The description of gene products is based on deduced amino acid sequences.

'References: (1) Koornneef et al. (1991); Lee et al. (1993). (2) Sung et al. (1992). (3) Shannon and Meeks-Wagner (1991, 1993); Alvarez et al. (1992) (4) Carpenter and Coen (1990); Coen and Meyerowitz (1991). (5) Coen et al. (1990); Schultz and Haughn (1991); Huala and Sussex (1992); Weigel et al. (1992). (6) Irish and Sussex (1990); Huijser et al. (1992); Mandel et al. (1992b). (7) Bowman et al. (1993). (8) Clark et al. (1993). (9) Leyser and Furner (1992). (10) Bowman et al. (1989, 1991b); Schwarz-Sommer et al. (1990). (11) Yanofsky et al. (1990); Bradley et al. (1993). (12) Kunst et al. (1989); Okamuro et al. (1993). (13) Sommer et al. (1990); Jack et al. (1992, 1993); Tröbner et al. (1992). (14) Schultz et al. (1991); Bowman et al. (1992). (15) Ma et al. (1991).

${ }^{\mathrm{d}} \mathrm{A}$ number of homologs have been isolated (see text for references): $A G$, from Brassica napus (BAG1), maize (ZAG1), petunia $(p M A D S 3)$ and tobacco (NAG1); AP3, from petunia (pMADS1); PI, from petunia (FBP1 and pMADS2), and tobacco (NTGLO). In addition, TM4 and TM6 from tomato share substantial sequence similarity with the Arabidopsis AP1 and AP3 (and Antirrhinum SQUA and DEFA) genes, respectively.

1990; Huijser et al. 1992; Mandel et al. 1992b; Weigel et al. 1992). Because flo/lfy and squa/ap1 mutants reiterate an earlier developmental program (inflorescence instead of flower), they could be considered heterochronic mutants. However, the nature of plant development is such that spatial arrangements are often laid out in a temporal sequence; therefore, the same abnormal development could be regarded as both a spatial and a temporal conversion (Coen et al. 1990).

In contrast to the genes promoting floral meristem initiation, the TFL1 gene inhibits floral meristem forma- tion (Shannon and Meeks-Wagner 1991; Alvarez et al. 1992; Schultz and Haughn 1993; Shannon and MeeksWagner 1993). Apart from being early flowering, the $t f 11$ mutants produce a determinate primary inflorescence with very few flowers and no secondary inflorescence (Fig. 1e), unlike the indeterminate wild-type inflorescence, which produces dozens of flowers as well as secondary and tertiary inflorescences. The tfl1 mutant inflorescence terminates with an abnormal flower consisting of two to three incomplete flowers. It seems that in the $t f 11$ mutants, the secondary inflorescence meristems 
are converted to floral meristems and that the primary inflorescence meristem is converted to two or three closely spaced floral meristems.

\section{Act 2: organ primordia initiation and identity}

Several Arabidopsis homeotic genes have been identified that affect the identity of floral organs, including $A P 1$, APETALA2 (AP2), APETALA3 (AP3), PISTILLATA (PI), and AGAMOUS (AG) (Table 1). Each of these genes controls the identity of two adjacent whorls of floral organs. Both the ap1 and ap2 mutations affect the organ identity in the outer two whorls, with severity of the phenotype dependent on the particular ap1 or ap2 mutant alleles. The strong ap1-1 mutant has a sepal-to-bract conversion in the first whorl, whereas weaker ap1 mutants have abnormal petals. In plants with one of the most severe ap2 alleles, the first and second whorl organs, if present, are converted from sepals and petals to carpels and stamens, respectively. Weaker alleles of ap2 lead to conversion of sepals to leaves and petals to petaloid stamens. The AP3 and PI genes are both required for correct second and third whorl organ types; $a p 3$ and pi mutants have conversion of petals to sepals and stamens to carpels. The $A G$ gene is required for determining the identities of stamens and the carpels. In ag mutant flowers, the six stamens are converted to petals and the ovary is replaced by a second $a g$ flower, such that the pattern of sepals, petals, and petals is repeated more than five times. The ag mutant phenotype indicates that $A G$ function is also required for the maintenance of a determinate floral meristem. That the number of floral organs is altered in $a p 2$ and $a g$ mutants indicates that these genes also function in regulating organ primordia initiation.

Mutations affecting organ identity have also been isolated in other plants (Meyerowitz et al. 1989), particularly in A. majus (Table 1). Many of the Antirrhinum mutations cause homeotic conversions similar to those found in Arabidopsis. The deficiens (defA) and globosa (glo) mutants have similar phenotypes to the Arabidopsis ap3 and $p i$ mutants, and so do mutants of another Antirrhinum gene, SEPALOIDEA (SEP). The Antirrhinum plena mutant is similar to the Arabidopsis ag mutant, with conversion of stamens to petals, and carpels to additional floral organs. In petunia, the blind mutant produces flowers with sepals exhibiting carpel features and conversion of petals (corolla) to staminoid organs (Tsuchimoto et al. 1993), similar to the flowers of weak Arabidopsis ap2 mutants. Another petunia floral mutant, green petal $(g p)$, has flowers with the petals converted to sepals (van der Krol et al. 1993).

Other mutants have flowers with altered numbers of organs. For example, the Arabidopsis superman (sup) mutant flowers are normal in the three outer whorls but produce more whorl(s) of stamens at the expense of the ovary (Schultz et al. 1991; Bowman et al. 1992). Studies of sup ap3 or sup pi double mutants suggest that $S U P$ negatively regulates $A P 3$ and $P I$ function in the fourth whorl. The Arabidopsis clavata1 (clv1) and clavata2 (clv2) mutant plants have ovaries consisting of more than the normal two carpels (Koornneef 1987). Recent studies indicate that clv1 mutants have a larger apical meristem and increased numbers of floral organs in all four whorls (Leyser and Furner 1992; Clark et al. 1993). Finally, mutations in the TOUSLED (TSL) gene cause a reduction in the number of floral organs in all whorls, as well as abnormal leaf morphology (Roe et al. 1993).

\section{The dialogues: genetic interactions}

\section{Interactions controlling floral meristem formation}

Double mutant analyses indicate that the meristem identity genes of Arabidopsis, LFY and AP1, interact with each other to control floral meristem formation (Fig. 2). The 1fy ap1 double mutant has a more complete conversion of floral to inflorescence meristem than either single mutant, suggesting that these genes function in parallel pathways to promote floral meristem formation and that these pathways are partially redundant. Similar studies indicate that the Antirrhinum FLO and SQUA genes also act in parallel pathways (Coen 1992). This functional parallel is further supported by the observations that $L F Y(F L O)$ is expressed in the ap1 (squa) mutant and that $S Q U A$ gene is expressed in the flo mutant (Huijser et al. 1992; Weigel et al. 1992). In addition, other genes contribute to the process of floral meristem initiation (Fig. 2). A variant allele of the Arabidopsis gene, CAULIFLOWER (CAL), was found to enhance the ap1 mutant phenotype, although the cal-1 allele alone has no phenotype, nor does the cal-1 allele enhance the

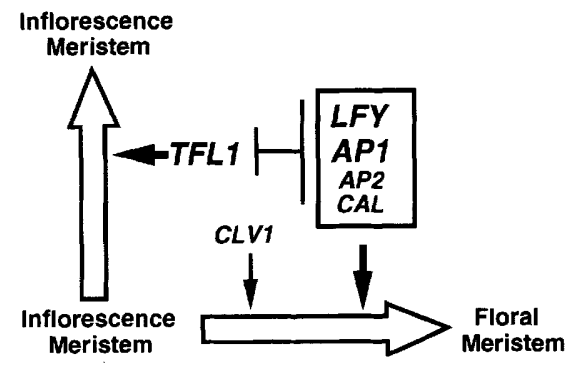

Figure 2. Control of transition from inflorescence to floral meristem in Arabidopsis. The meristem identity genes $L F Y$ and $A P 1$ are two main players promoting floral meristem initiation, whereas $A P 2$ and $C A L$ have little or no effect on meristem identity in the wild-type LFY AP1 background. However, cal enhances the effect of $a p 1$, and ap2 enhances those of both lfy and $a p 1$, on meristem identity. In addition, $A P 1$ and $C A L$ together positively affect the expression of $L F Y$ and $A P 1$. The box around these four genes indicates the positive genetic interactions and/or functional redundancy among these genes. CLV1 also promotes the transition to floral meristem. TFL1 promotes inflorescence meristem and antagonizes $L F Y, A P 1$, and $A P 2$. Based on information from the following references, Alvarez et al. (1992); Huala and Sussex (1992); Weigel et al. (1992); Bowman et al. (1993); Clark et al. (1993); Okamuro et al. (1993); Schultz and Haughn (1993); Shannon and Meeks-Wagner (1993); and Weigel and Meyerowitz (1993c). $\rightarrow$ ) Positive interaction and $(-1)$ negative interaction. 
phenotype of a strong lfy mutant (Bowman et al. 1993). In the ap1 mutant background, $C A L$ has been shown to positively affect the expression of both the Arabidopsis LFY and AP1 genes. It is possible that in the wild type, the combination of both LFY and AP1 activities is in excess of the minimal requirement (threshold) for floral meristem formation, and $C A L$ is not necessary. In ap1 mutants, the total activity for floral meristem is reduced to near the threshold, and further reduction due to a defect in $C A L$ function manifests as a more severe phenotype than those of the ap1 single mutants. Double mutant analyses also revealed that the organ identity gene AP2 contributes to meristem identity. Although ap2 single mutants show no defect in floral meristem formation, ap 2 mutations enhance the ap1 or lfy mutant phenotypes, leading to a more complete conversion of floral to inflorescence meristems. One explanation is that AP2 is required for floral meristem in the absence of LFY or AP1 activities; this is consistent with the finding that $A P 2$ is also expressed at stages before floral organ formation. Finally, clv1 mutations also enhance the phenotypes of lfy and lfy ap1 mutants, indicating that CLV1 is also involved in determining meristem identity. These double and triple mutant analyses indicate that although $L F Y$ and $A P 1$ are the major functions that promote floral meristem formation, $C A L, A P 2$, and $C L V 1$ also contribute to this process.

Contrary to these positively acting genes, the Arabidopsis TFL1 gene inhibits floral meristem development. Moreover, on the basis of double mutant studies it was proposed that TFL1 antagonizes $L F Y, A P 1$, and $A P 2$ (Fig. 2). This is supported by the observation that the expression of $L F Y$ and $A P 1$ expands in a $t f 11$ mutant to include the meristems occupying the positions of the wild-type inflorescence meristems (Weigel et al. 1992; Bowman et al. 1993; Gustafson-Brown et al. 1994). Although ap1 mutations do not, lfy mutations partially suppress $t f 11$ mutant phenotypes, especially under short-day conditions (Alvarez et al. 1992; Bowman et al. 1993; Schultz and Haughn 1993; Shannon and Meeks-Wagner 1993). Furthermore, combinations of $1 f y$ and $a p 1$, or lfy and $a p 2$, mutations clearly suppress tfl1 meristem phenotypes (Schultz and Haughn 1993).

At least part of the function of the Arabidopsis meristem identity genes $L F Y$ and $A P 1$ is to regulate the expression of floral organ identity genes (Weigel and Meyerowitz 1993al, bridging these two stages of flower development. Analyses of the expression patterns of $A P 3$, $P I$, or $A G$ in $1 f y$ and ap1 single or double mutants indicate that LFY and APl synergistically activate the expression of $A P 3$ and $P I$, and regulate $A G$ expression pattern (Weigel and Meyerowitz 1993a). These results are consistent with the finding that the Arabidopsis $L F Y$ and $A P 1$ genes are expressed in developing flowers during floral organ primordia formation, in addition to being expressed in earlier stages of floral meristems (Mandel et al. 1992b; Weigel et al. 1992). Likewise, the Antirrhinum $F L O$ and SQUA genes are also expressed in early floral primordia at the time of organ primordia initiation /Coen et al. 1990; Huijser et al. 1992). On the basis of the tran- sient expression of $F L O$ in whorls 1, 2, and 4, it was proposed that FLO activates some of the organ identity genes sequentially (Coen et al. 1990). It seems that the meristem identity genes function to set up the stage on which the floral homeotic genes play their roles in controlling the organ identities /see Fig. 3 and discussion below).

\section{Models for the specification of floral organ identity}

A model (the ABC model, Fig. 3a) for the determination of floral organ identity was proposed on the basis of genetic analyses in Arabidopsis and Antirrhinum. The Arabidopsis and Antirrhinum mutant phenotypes indicate that $A P 2$ is essential for the A function, that the Arabidopsis AP3 and PI genes (DEFA and GLO from Antirrhinum) are components of the $\mathbf{B}$ function, and that the Arabidopsis AG gene (PLENA from Antirrhinum) is a necessary part of the $\mathbf{C}$ function, as shown in Fig. $3 \mathrm{~b}$. The proposed domains of gene action are supported by the expression patterns of several homeotic genes, including the Arabidopsis $A G$ and $A P 3$, and the Antirrhinum $D E F A, G L O$, and PLENA genes. An important aspect of this model is that the $\mathbf{A}$ and $\mathbf{C}$ functions antagonize each other, such that $\mathbf{A}$ inhibits $\mathbf{C}$ in whorls 1 and 2, and $\mathbf{C}$ inhibits $\mathbf{A}$ in whorls 3 and 4 . This antagonism is supported by the fact that the expression of $A G$ and its petunia homolog (pMADS3) expands outward to all floral whorls in the Arabidopsis ap2 and the petunia blind mutant flowers, respectively. Moreover, ectopic expression of $A G$ or the $A G$ homologs from Brassica, petunia, and tobacco in the outer whorls of transgenic flowers results in ap2-like flowers, and a similar ectopic expression of the PLENA gene in Antirrhinum leads to the ovulata (ap2-like) mutant phenotype (Mandel et al. 1992a; Mizukami and Ma 1992; Bradley et al. 1993; Kempin et al. 1993; Tsuchimoto et al. 1993). The A-C antagonism also predicts that in the ag mutant, the $\mathbf{A}$ function would expand to whorls 3 and 4 and inhibit $A G$ expression (Fig. 3b).

The ABC model is similar to an earlier model based on mutant analysis in Antirrhinum, which proposed that there are two functions (equivalent to $\mathbf{B}$ and $\mathbf{C}$ of the $\mathbf{A B C}$ model) but no equivalent to the $\mathbf{A}$ function (Schwarz-Sommer et al. 1990). This model can be reconciled with the $\mathbf{A B C}$ model because $\mathbf{A}$ and $\mathbf{C}$ are mutually exclusive and $\mathbf{A}$ is equivalent of the absence of $\mathbf{C}$. Because the expression of the Antirrhinum $\mathbf{C}$ function gene PLENA has now been shown to be negatively regulated in whorls 1 and 2 (Bradley et al. 1993), the yet to be identified negative regulator may be an $\mathbf{A}$ function component in Antirrhinum. Other models for organ identity were also proposed in which the identity of an inner (later) whorl of organs was dependent on the organ identity of adjacent outer whorl(s) (Heslop-Harrison 1963; Green 1988). Because many mutants exist that show normal organs in some whorls and abnormal organs in the next whorl or vice versa, these sequential models are not consistent with the genetic results.

Although the simple ABC model for organ identity is 

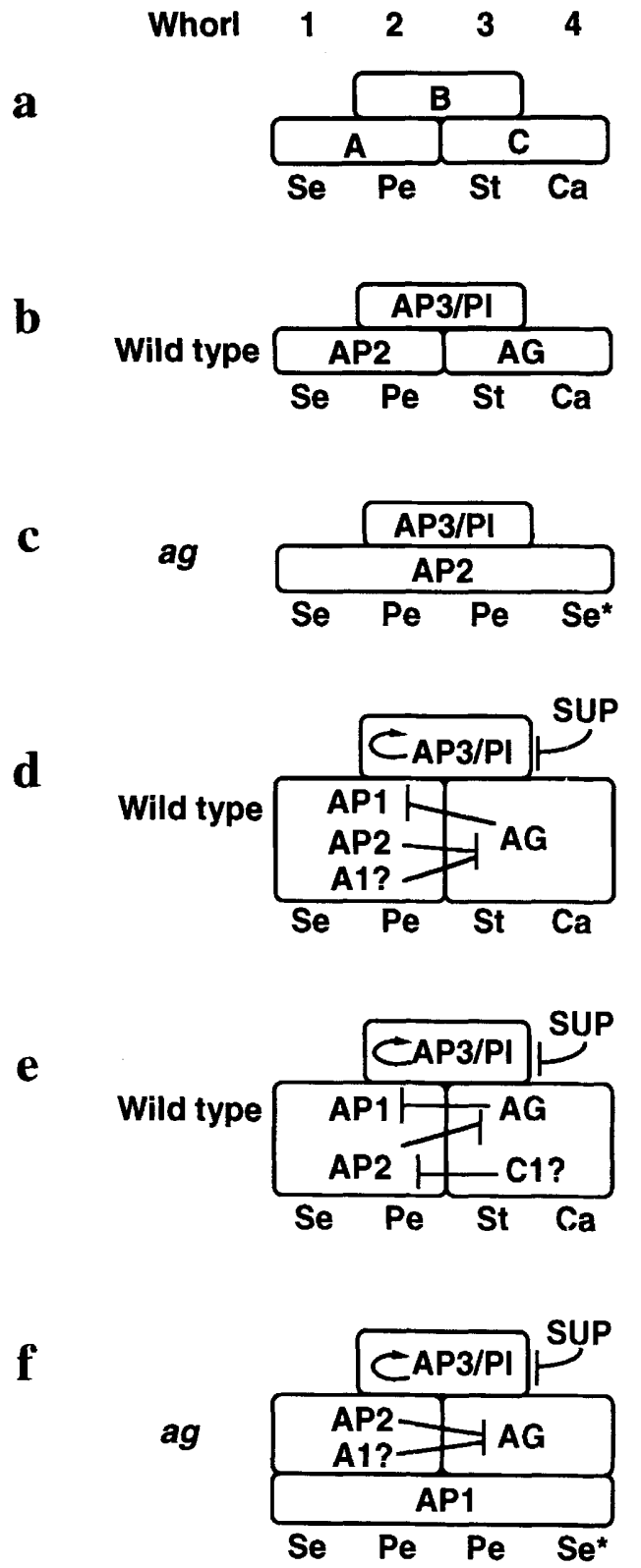

Figure 3. An illustration of the $\mathbf{A B C}$ floral organ identity model and revised models, using Arabidopsis as an example. According to the ABC model (Bowman et al. 1991b; Coen and Meyerowitz 1991; Meyerowitz et al. 1991), the wild-type floral organ identity is controlled by three functions, $\mathbf{A}, \mathbf{B}$, and $\mathbf{C}$, which are localized to overlapping regions of the floral meristem $(a)$. The floral organs are sepal $(\mathrm{Se}) ;$ petal $(\mathrm{Pe})$; stamen $\mid \mathrm{St})_{\text {; }}$ and carpel $(\mathrm{Ca})$. The $\mathbf{A}$ function alone leads to sepals, whereas the combination of $\mathbf{A}$ and $\mathbf{B}$ functions dictates that petals are formed. The $\mathbf{B}$ and $\mathbf{C}$ functions together control the identity of stamen, and the $\mathbf{C}$ function alone results in the formation of carpels. In a wild-type Arabidopsis flower $\{b \mid, A P 2$ and $A G$ are representatives of the $\mathbf{A}$ and $\mathbf{C}$ functions, respectively, whereas $A P 3$ and $P I$ are both components of the $\mathbf{B}$ function. The domains of action for these genes correspond to their expression patterns (Drews et al. 1991; Jack et al. 1992; Schwarz-Sommer et al. 1992; Tröbner et al. 1992; Bradley et al. 1993), with the exception of $A P 2$ (see below in revised models). In the ag mutant flower $(c)$, the A function (AP2) expands to the inner two whorls, leading to the conversion of stamens and carpels to petals and sepals (with secondary flower), respectively. The domains of action of organ identity genes for a wild-type Arabidopsis flower according to two revised models (see text) are shown in $d$ and $e$. (d) A revised model with a proposed component of function $\mathbf{A}(\mathrm{Al})$ needed to negatively regulate $A G$ expression. In whorls 3 and $4, \mathrm{AP} 2$ does not repress $A G$ expression in the absence of A1. Furthermore, AG negatively regulates $A P 1$ expression in whorls 3 and 4 . In addition, $A P 3$ and PI are negatively regulated in whorl 4 by SUP. AP2 is not placed in whorls 3 and 4 because AP2 does not seem to play a role in determining organ identity in these whorls, although its mRNA is present in these whorls. (e) An alternative revised model for organ identity, with a proposed component of function $\mathrm{C}(\mathrm{Cl})$, that negatively regulates AP2 function (but not expression). In whorls 1 and 2, the absence of $\mathrm{Cl}$ allows $A P 2$ to function as an organ identity gene and to repress $A G$ expression. The other regulations are the same as in $d$. According to the revised model in $(d)$, in the ag mutant flower $(f), A G$ expression remains limited to whorls 3 and 4, because AP2 and A1 continue to function only in whorls 1 and 2. AP1 expression does expand to the inner whorls. The revised models are based on the information from the following references: AP2 expression (Okamuro et al. 1993); ap1 phenotypes and expression (Irish and Sussex 1990; Mandel et al. 1992b; Bowman et al. 1993; Gustafson-Brown et al. 1994); $A G$ expression in ag mutant (Gustafson-Brown et al. 1994); autoregulation of $A P 3$ and PI (Jack et al. 1992); and regulation of AP3 and PI by SUP (Bowman et al. 1992; E.M. Meyerowitz, pers. comm.). $(\rightarrow \mid$ Positive interaction. $(-1)$ Negative interaction. very attractive, it needs to be revised to account for more recent observations. First, more is now known than before about the $\mathbf{A}$ function and the antagonism between $\mathbf{A}$ and $\mathbf{C}$ functions. The phenotypes of ap1 and ap1 ap2 mutants indicate that $A P 1$ is a component of the $\mathbf{A}$ function. In addition, $A P 1$ is expressed only in the outer two whorls of the wild-type flowers but is also ectopically expressed in the inner whorls of ag mutant flowers, indicating that $A G$ negatively regulates $A P 1$ expression (Mandel et al. 1992b; Gustafson-Brown et al. 1994). Furthermore, $A G$ expression pattern in the ag-1 mutant flowers is the same as that in the wild-type flowers (Gustafson-Brown et al. 1994), indicating that the factors(s) regulating $A G$ expression is not affected by the ag-1 mutation. Finally; $A P 2$ is expressed in all whorls (Okamuro et al. 1993) and it is needed to repress $A G$ expression in the outer two whorls; therefore, there may either be another factor (A1, Fig. 3d) in these whorls that is required for this repression, or an inhibitor (C1, Fig. 3e) of $A P 2$ function (but not expression) in the inner two whorls. Because $A P 1$ and $A P 2$ are each essential components of the $\mathbf{A}$ function, the mutual antagonism between the $\mathbf{A}$ and $\mathbf{C}$ functions is accounted for by the inhibition of $A G$ expression by AP2 (with the proposed moderation by $\mathrm{A} 1$ or $\mathrm{C} 1$ ) and the inhibition of $A P 1$ expression by $\mathrm{AG}$. The difference between the effects of ap1 and ap2 mutation on organ identity can be explained by the ectopic expression in the latter case of $A G$, which is required for stamen and carpel identities. Moreover, the phenotypes of $35 \mathrm{~S}-A G$ transgenic flowers can be accounted for by the ectopic expression of $A G$ and the inhibition of $A P 1$ in the outer two whorls. On the other hand, in ag mu- 
tants, the ectopic expression of $A P 1$ and the lack of $A G$ function (but not $A G$ expression) in the inner whorls result in the replacement of stamens and carpels by petals and sepals (Fig. 3f). A second aspect of the revisions involves the regulation of the $\mathbf{B}$ function genes. The analyses of expression of the Arabidopsis AP3 gene in the ap3 or pi mutant, and that of the Antirrhinum DEFA and $G L O$ genes in $\operatorname{def} A$ or glo mutants, indicate that each gene pair regulates its own expression. AP3 and $P I$ are both required for persistent, although not the initial, expression of $A P 3$, whereas $D E F A$ and $G L O$ are both needed for the elevated, but not low, levels of expression for each gene. In addition to the autoregulation, the $A r$ abidopsis AP3 and PI genes are regulated by AP2 and SUP. The wild-type AP2 function is required for a normal level of $A P 3$ expression at early stages and for any expression at later stages. The negative regulation of $A P 3$ and $P I$ by SUP at the center of the flower (Figure $3 \mathrm{~d}$ and e), as suggested from genetic studies, has been confirmed by the finding that expression of both $A P 3$ and $P I$ expands toward the center in the sup mutant flower. Although the revised $\mathbf{A B C}$ models are probably still simplifications of a more complex reality, they contain a number of testable hypotheses and provide a framework for understanding the mechanisms that specify organ identities.

\section{Other roles: possible late functions of the floral genes}

Molecular analysis of floral genes not only supports predictions from genetic studies but also suggests functions of these genes other than specifying meristem or organ identity. The expression of the floral meristem identity genes, FLO from Antirrhinum and LFY from Arabidopsis, was observed in developing floral organs (Coen et al. 1990; Weigel et al. 1992), suggesting that FLO and $L F Y$ may have other functions in addition to specifying meristem identity. However, the nature of the potential late functions is not known. The floral organ identity genes, $A G, A P 1$, and AP3 from Arabidopsis, and PLENA, $S Q U A, D E F A$, and GLO from Antirrhinum, are also expressed during later stages of floral organ development, after the organ types have been determined. In particular, $A G$ is expressed in specific cell types in late stamens and gynoecium, as are the $A G$ homologs from Antirrhinum (PLENA) and maize (ZAG1) (Bowman et al. 1991a; Bradley et al. 1993; Schmidt et al. 1993). Furthermore, ectopic expression of $A G$ or its Brassica homolog (BAG1) leads to sterility in transgenic plants (Mandel et al. 1992a; Mizukami and Ma 1992). These results suggest that $A G$ and its homologs are required for proper differentiation of specific cell types during late floral organ differentiation. Expression of DEFA is also found throughout organ development. Moreover, small sectors of as few as four petal cells have been observed in the second whorl sepals (converted from petals) of plants carrying a transposon insertion in DEFA (Coen and Meyerowitz 1991). These petal cells most likely result from the restoration of wild-type DEFA function after the excision of the transposon. The expression and somatic reversion results of the DEFA gene suggest that it functions throughout organ development. Extended gene action for the Arabidopsis AP3 gene has also been suggested by the analysis of a temperature-sensitive $a p 3$ mutant (Bowman et al. 1989).

\section{The players: members of a conserved gene family}

The sequences of many of the floral genes reveal that they are members of a conserved gene family. The amino-terminal region of the predicted Arabidopsis AG protein (Yanofsky et al. 1990) shares striking sequence similarity with the DNA-binding domains of the human serum response factor (SRF) and a regulator of yeast celltype specific genes, MCM1 (Norman et al. 1988; Passmore et al. 1988), as well as a region of a yeast regulator of arginine metabolic genes, ARG80 (Dubois et al. 1987). The Antirrhinum DEFA gene also encodes a protein with a similarly conserved motif (Sommer et al. 1990). The conserved region found in these genes has been designated the MADS box (for MCM1, AG and ARG80, DEFA, and SRF; Schwarz-Sommer et al. 1990). The fact that $A G$ and $D E F A$ genes function in different pathways controlling flower development and still share a conserved MADS box, and the fact that the MADS box is an ancient motif, led to the proposal that other floral regulatory genes may also contain a MADS box (Ma et al. 1991). Several Arabidopsis and Antirrhinum floral homeotic genes have recently been shown to contain a MADS box (see Table 1). The petunia DEFA (AP3) homolog, $p M A D S 1$, was found to correspond to the floral homeotic gene GP (van der Krol et al. 1993). The gp mutant (a large deletion) has a petal-to-sepal conversion but nearly normal stamens, whereas $A P 3$ and DEFA are needed for petal and stamen formation. It is possible that in petunia, a gene functionally overlapping with pMADS1 acts in the stamens; this gene may even be a MADS box gene similar to $P M A D S 1$, as petunia seems to have two genes very similar to the Antirrhinum GLO (see below). The phenotypic difference between $g p$ and $\operatorname{def} A$ (or $a p 3$ ) indicates that in different plants the B function genes may be functionally distinct (van der Krol et al. 1993).

The complexity of flower development suggests that other regulatory proteins are probably involved in addition to those identified by genetic analysis (Table 1). Using $A G$ sequences as probes, six additional MADS box genes were isolated from Arabidopsis and designated AGL1-AGL6, for AG-Like (Ma et al. 1991). Five of these genes are flower specific, suggesting that, like $A G$, they encode regulators of flower development. In particular, AGL1 is expressed in carpels. Five MADS box genes were isolated from tomato and designated TM3, TM4, TM5, TM6, and TM8 (Pnueli et al. 1991). All but TM3 are preferentially expressed in flowers. Among these, TM6 and TM4 are most similar in their sequences to DEFA and SQUA from Antirrhinum, respectively, and TM5 may be a homolog of $A G L 6$ from Arabidopsis. In addition to pMADS1 and $p M A D S 3$, other MADS box genes from petunia include $f b p 1, f b p 2, p M A D S 2$, and $p M A D S 4$ (Ange- 
nent et al. 1992; Tsuchimoto et al. 1993; van der Krol et al. 1993). All except $p M A D S 4$ are expressed specifically in flowers. Furthermore, the expression of both $f b p 1$ and pMADS2 is limited to the second and third whorls and is altered in the $g p$ mutant, and the $f b p 1$ and $p M A D S 2$ sequences are most similar to that of the Antirrhinum GLO gene (Angenent et al. 1992, 1993; van der Krol et al. 1993). MADS box genes have also been isolated from the monocot maize (Schmidt et al. 1993). In addition to the homolog of the Arabidopsis AG gene (ZAG1), there is another maize MADS box gene (ZAG2), which is most similar to the Arabidopsis AGL5 gene in sequence and expression pattern. It is intriguing that ZAG1 and ZAG2 map very close to two loci known to affect flower development, Polytypic ear (Pt) and Tassel seed4 (TS4), respectively. The fact that several of the genetically defined floral homeotic genes in both Arabidopsis and Antirrhinum are MADS box genes, and that additional MADS box-containing genes from several plants are also flower specific, suggests that a family of MADS box genes function as regulators during flower development.

In addition to the MADS domain, the plant MADS domain proteins share a second conserved region. Although the sequences in this region are not as highly conserved as the MADS domain sequences, they show substantial similarity to a portion of the intermediate filament protein keratin; therefore, the region was designated the $\mathrm{K}$ domain and may potentially form amphipathic (coiled-coil) helices and possibly mediate proteinprotein interaction (Ma et al. 1991; Pnueli et al. 1991). This is consistent with the finding that temperature-sensitive mutations in both the Arabidopsis AP3 gene and the Antirrhinum DEFA gene are localized to this region and affect a lysine residue near either the caroboxy-terminal (ap3-1) or the amino-terminal (defA-101) ends of the K domain (Jack et al. 1992; Schwarz-Sommer et al. 1992). Both of these lysines are highly conserved among the $\mathrm{K}$ domains, suggesting that they may play a structural or functional role shared by these proteins.

\section{Backstage: molecular mechanisms}

The extensive in vivo and in vitro studies on SRF and MCM1 can provide useful hints about the mechanism of plant MADS box gene functions. SRF and MCMl proteins have overlapping binding sequence specificities, with consensus target sequences containing a CArG box $(\mathrm{CC} \mid \mathrm{A} / \mathrm{T})_{6} \mathrm{GG}$; Pollock and Treisman 1990; Wynne and Treisman 1992). Containing the same type of conserved motif, the plant MADS domain proteins may also bind to similar sequences. In vitro experiments indicate that $A G$ binds to sequences containing a CArG box (Mueller and Nordheim 1991; Huang et al. 1993; Shiraishi et al. 1993). Studies with the Antirrhinum DEFA and GLO proteins indicate that neither can bind DNA alone; however, together they bind as heterodimers to sequences with a CArG box (Schwarz-Sommer et al. 1992; Tröbner et al. 1992). Similarly, the Arabidopsis AP3 and PI proteins interact in vitro (E.M. Meyerowitz, pers. comm.). These results suggest that plant MADS domain proteins are probably sequence-specific DNA-binding proteins, as are SRF and MCM1. Furthermore, the regulatory functions of the floral homeotic genes indicate that the mutant phenotypes are probably attributable to the alteration in the transcription of genes normally controlled by the MADS domain proteins.

Many of the floral homeotic genes are expressed in more than one type of floral organs. For example, $A G$ is expressed in stamens and carpels (Bowman et al. 1991a; Drews et al. 1991), whereas AP3 is expressed in petals and stamens (Jack et al. 1992). Some of the morphological differences of the organs may be attributable to the activities of different sets of genes regulated in different organs by the same MADS domain regulator, perhaps through interactions with other factors, as is the case for MCM1. MCM1 is expressed in both the MATa and MAT $\alpha$ haploid cells. However, different genes are expressed in these cell types because of the combined functions of MCM1 and other factors (Herskowitz 1990). In the MATa cells, MCM1 alone activates the a-specific genes. In the MAT $\alpha$ cells, MCMI binds cooperatively with MAT $\alpha 1$ to the promoters of $\alpha$-specific genes to activate them while the MCM1-MAT $\alpha 2$ complex binds the upstream region of a-specific genes to repress them. It is possible that plant MADS domain proteins interact with other factors through the $\mathrm{K}$ domain. The same MADS domain protein may interact with different accessory factors in different cells. For example, AG may regulate stamen and carpel development by cooperating with stamen- and carpel-specific factors.

\section{Conclusion}

From the extensive genetic and molecular studies, it is clear that many regulatory proteins function in a complex network to control flower development. In this network, multiple genes/proteins interact with each other; the interaction could be either positive or negative, and at any level from transcription to protein-protein interaction. The parts of this network that operate at different developmental stages are connected in at least two ways. First, many of the genes, such as TFL1 and AP1, are involved in more than one stage of flower development, suggesting that a single regulatory protein may interact with different factors, and/or control different genes, at different stages of development. Second, genes required at one stage can regulate genes that function at the next stage. This was clearly shown for the Arabidopsis floral meristem genes $L F Y$ and $A P 1$, which regulate the expression of the organ identity genes $A P 3, P I$, and $A G$. In addition, many of the regulatory genes identified thus far are members of the MADS box gene family, which includes several additional flower-specific MADS box genes. The fact that MADS domain proteins from mammals and yeast are known to interact with different proteins to differentially regulate transcription suggests a mechanism for the multifaceted functions of many of the floral genes. Although most of the regulatory genes isolated thus far seem to encode transcription factors, other types of proteins are likely to participate in the 
network. Furthermore, some of the genes controlling flower development may also function during vegetative development. For instance, the Arabidopsis TSL gene is expressed in both floral and vegetative organs and encodes a protein with a domain similar to protein kinases; in addition, the tsl mutants have abnormal leaves and flowers, indicating that the wild-type gene function is required for normal leaf and floral development (Roe et al. 1993). The Arabidopsis AP2 gene may be another example because it is also expressed in vegetative organs (Okamuro et al. 1993).

These studies also provide a large amount of new information supporting the idea advanced previously by Coen and Meyerowitz (1991) that similar genes operate in the two distantly related plants Arabidopsis and Antirrhinum. Several pairs of homologs have now been isolated that function in similar ways in these two plants. Furthermore, homologs of floral genes discovered in these two plants have now been isolated in many plants, including the monocot maize. These results and the observation that mutants similar to those in Arabidopsis and Antirrhinum have been found in many other plants indicate that much of the regulatory network is conserved in flowering plants.

How, then, can a conserved network of genes control the development of such diverse array of flowers? One possibility is that the homologs do not function in exactly the same way in each plant. This is the case for all of the pairs of homologs between Arabidopsis and An. tirrhinum. For example, FLO and $L F Y$ are slightly different in that flo mutants show a complete conversion of flower to inflorescence, whereas $1 \mathrm{fy}$ mutants show only partial conversions. Another example is the petunia $g p$ mutant, which has a conversion of petals to sepals, but nearly normal stamens, while homologous mutations in Arabidopsis and Antirrhinum affect both petals and stamens. There are many possible mechanisms that could account for the divergence; for example, the homologs may interact with other factors or bind to target sites differently. In the case of the $g p$ mutant, petunia may have a redundant gene function in stamens but not petals. Another way diversity can be achieved is by more dramatic changes: addition or elimination of a gene. The Arabidopsis TFL1 and Antirrhinum CEN genes, which when eliminated lead to the formation of a terminal flower, may be examples of such changes. It is possible that in plants with terminal flowers, the equivalent of TFL1 or CEN function is absent (Carpenter and Coen 1990). Another example is the CYC gene of Antirrhinum, which is required for the bilateral symmetry of the flower (Carpenter and Coen 1990). Therefore, it is likely that with variations on a conserved network of regulators, nature has created such an enormous amount of diversity in floral forms.

The results obtained thus far also raise many more questions and suggest possible ways to address these questions. How do the developmental and environmental signals regulate floral induction and the establishment of an inflorescence meristem? The cloning of the $E M F$ and TFL1 genes, as well as the late flowering genes, will go a long way to uncover some of the mechanisms. What controls the floral meristem genes? Analysis of expression of the floral meristem genes in mutants affecting floral induction may provide some answers. In addition, molecular studies that identify factors that interact with the promoters of these genes can also be very powerful. How do the meristem genes and others regulate the floral homeotic genes? AP1 and SQUA (MADS box) are likely to be transcription factors, and FLO and LFY may also be; it will be particularly interesting to learn whether they interact with other factors, and what are the direct target genes. What are the potential factors with which the homeotic gene products interact? And what target genes do the homeotic genes regulate? These questions go to the heart of homeotic gene functions and may be solved with a combination of genetic, molecular, and biochemical approaches.

In short, the fascinating story of flower development that we have learned so far is only the early part of an exciting drama. As it unfolds, new players will come onto the scene, and new secrets will be unlocked to provide us with further intriguing insights into the control of flower development.

\section{Acknowledgments}

I apologize for not citing some of the earlier references because of space constraints. I thank J. Bowman, N.-H. Chua, C. Gustafson-Brown, S. Kempin, E. Meyerowitz, J. Okamuro, J. Roe, R. Schmidt, D. Smyth, S. Tsuchimoto, A. van der Krol, D. Weigel, and $M$. Yanofsky for communicating results prior to publication, and for discussion on the revised models for floral organ identity, and N. Comfort, C. Flanagan, D. Helfman, D. Kostic, E. Meyerowitz, P. Rubinelli, P. Springer, Z. Tao, M. Tudor, T. Volpe, D. Weigel, C. Weiss, M. Yanofsky and the anonymous reviewers for helpful comments on this manuscript. The research in my laboratory was supported by the Cold Spring Harbor Laboratory Robertson Fund and by grants from the National Science Foundation (DCB91-05260) and the U.S. Department of Agriculture (92-01551).

\section{References}

Alvarez, J., C.L. Guli, X.-H. Yu, and D.R. Smyth. 1992. terminal flower: A gene affecting inflorescence development in Arabidopsis thaliana. Plant 1. 2: 103-116.

Angenent, G.C., M. Busscher, J. Franken, J.N.M. Mol, and A.J. van Tunen. 1992. Differential expression of two MADS box genes in wild-type and mutant petunia flowers. Plant Cell 4: 983-993.

Angenent, G.C., J. Franken, M. Busscher, L. Colombo, and A.J. van Tunen. 1993. Petal and stamen formation in petunia is regulated by the homeotic gene fbp1. Plant $/$. 4: 101-112.

Araki, T. and Y. Komeda. 1993. Analysis of the role of the lateflowering locus, GI, in the flowering of Arabidopsis thaliana. Plant J. 3: 231-239.

Bernier, G., A. Havelange, C. Houssa, A. Petitjean, and P. Lejeune. 1993. Physiological signals that induce flowering. Plant Cell 5: 1147-1155.

Bowman, J.L., D.R. Smyth, and E.M. Meyerowitz. 1989. Genes directing flower development in Arabidopsis. Plant Cell 1: 37-52.

Bowman, J.L., G.N. Drews, and E.M. Meyerowitz. 1991a. Ex- 
pression of the Arabidopsis floral homeotic gene $A G A$ MOUS is restricted to specific cell types late in flower development. Plant Cell 3: 749-758.

Bowman, J.L., D.R. Smyth, and E.M. Meyerowitz. 1991b. Genetic interactions among floral homeotic genes of Arabidopsis. Development 112: 1-20.

Bowman, J.L., H. Sakai, T. Jack, D. Weigel, U. Mayer, and E.M. Meyerowitz. 1992. SUPERMAN, a regulator of floral homeotic genes in Arabidopsis. Development 114: 599-615.

Bowman, J.L., J. Alvarez, D. Weigel, E.M. Meyerowitz, and D.R. Smyth. 1993. Control of flower development in Arabidopsis thaliana by APETALA1 and interacting genes. Development 119: $721-743$.

Bradley, D., R. Carpenter, H. Sommer, N. Hartley, and E.S. Coen. 1993. Complementary floral homeotic phenotypes result from opposite orientations of a transposon at the plena locus of Antirrhinum. Cell 72: 85-95.

Burn, J.E., D.J. Bagnall, J.D. Metzger, E.S. Dennis, and W.J. Peacock. 1993. DNA methylation, vernalization, and the inhibition of flowering. Proc. Natl. Acad. Sci. 90: 287-291.

Carpenter, R. and E.S. Coen. 1990. Floral homeotic mutations produced by transposon-mutagenesis in Antirrhinum majus. Genes \& Dev. 4: 1483-1493.

Clark, S.E., M.P. Running, and E.M. Meyerowitz. 1993. CLAV$A T A 1$, a regulator of meristem and floral development in Arabidopsis. Development 119: 397-418.

Coen, E.S. 1991. The role of homeotic genes in flower development and evolution. Annu. Rev. Plant Physiol. Plant Mol. Biol. 42: 241-279.

- 1992. Flower development. Curr. Opin. Cell Biol. 4: 929-933.

Coen, E.S. and R. Carpenter. 1992. The power behind the flower. New Sci. 134: 24-27.

Coen, E.S. and E.M. Meyerowitz. 1991. The war of the whorls: Genetic interactions controlling flower development. $\mathrm{Na}$ ture 353: 31-37.

Coen, E.S., J.M. Romero, S. Doyle, R. Elliot, G. Murphy, and R. Carpenter. 1990. floricaula: A homeotic gene required for flower development in Antirrhinum majus. Cell 63: 13111322.

Drews, G.N., J.L. Bowman, and E.M. Meyerowitz. 1991. Negative regulation of the Arabidopsis homeotic gene $A G A$ MOUS by the APETALA2 product. Cell 65: 991-1002.

Dubois, E., J. Bercy, and F. Messenguy. 1987. Characterization of two genes, $A R G R I$ and $A R G R I I I$, required for specific regulation of the arginine metabolism in yeast. Mol. Gen. Genet. 207: 142-148.

Green, P.B. 1988. A theory for inflorescence development and flower formation based on morphological and biophysical analysis in Echeveria. Planta 175: 153-169.

Gustafson-Brown, C., B. Savidge, and M.F. Yanofsky. 1994. Regulation of the Arabidopsis floral homeotic gene APETALA1. Cell 76: 131-143.

Herskowitz, I. 1990. A regulatory hierarchy for cell specialization in yeast. Nature 342: 749-757.

Heslop-Harrison, J. 1963. Sex expression in flowering plants. Brookhaven Symp. Biol. 16: 109-125.

Huala, E. and I. M. Sussex. 1992. LEAFY interacts with floral homeotic genes to regulate Arabidopsis floral development. Plant Cell 4: 901-913.

Huang, H., Y. Mizukami, Y. Hu, and H. Ma. 1993. Isolation and characterization of the binding sequences for the product of the Arabidopsis floral homeotic gene AGAMOUS. Nucleic Acid Res. 21: 4769-4776.

Huijser, P., J. Klein, W.-E. Lönnig, H. Meijer, H. Saedler, and H. Sommer. 1992. Bracteomania, an inflorescence anomaly, is caused by the loss of function of the MADS-box gene squamosa in Antirrhinum majus. EMBO J. 11: 1239-1249.

Irish, V.F. and I.M. Sussex. 1990. Function of the apetala-1 gene during Arabidopsis floral development. Plant Cell 2: $741-$ 753.

Jack, T., L.L. Brockman, and E.M. Meyerowitz. 1992. The homeotic gene APETALA3 of Arabidopsis thaliana encodes a MADS box and is expressed in petals and stamens. Cell 68: 683-697.

Jack, T., L.E. Sieburth, and E.M. Meyerowitz. 1993. Genes that control flower development in Arabidopsis. Sem. Dev. Biol. 4: 51-63.

Kempin, S.A., M.A. Mandel, and M.F. Yanofsky. 1993. Conversion of perianth into reproductive organs by ectopic expression of the tobacco floral homeotic gene NAG1. Plant Phys iol. 103: 1041-1046.

Koornneef, M. 1987. Linkage map of Arabidopsis thaliana $(2 \mathrm{n}=10)$. In Genetic maps 1987: A compilation of linkage and restriction maps of genetically studied organisms (ed. S.J. O'Brien), pp. 742-745. Cold Spring Harbor Laboratory, Cold Spring Harbor, New York.

Koornneef, M., C.J. Hanhart, and J.H. van der Veen. 1991. A genetic and physiological analysis of late flowering mutants in Arabidopsis thaliana. Mol. Gen. Genet. 229: 57-66.

Kunst, L., J.E. Klenz, J. Martinez-Zapater, and G.W. Haughn. 1989. AP2 gene determines the identity of perianth organs in flowers of Arabidopsis thaliana. Plant Cell 1: 1131-1135.

Lee, I., A. Bleecker, and R. Amasino. 1993. Analysis of naturally occuring late flowering in Arabidopsis thaliana. Mol. Gen. Genet. 237: 171-176.

Leyser, H.M.O. and I.J. Furner. 1992. Characterization of three shoot apical meristem mutants of Arabidopsis thaliana. Development 116: 397-403.

Ma, H., M.F. Yanofsky, and E.M. Meyerowitz. 1991. AGL1$A G L 6$, an Arabidopsis gene family with similarity to floral homeotic and transcription factor genes. Genes \& Dev. 5: 484-495.

Mandel, M.A., J.L. Bowman, S.A. Kempin, H. Ma, E.M. Meyerowitz, and M.F. Yanofsky. 1992a. Manipulation of flower structure in transgenic tobacco. Cell 71: 133-143.

Mandel, M.A., C. Gustafson-Brown, B. Savidge, and M.F. Yanofsky. 1992b. Molecular characterization of the Arabidopsis floral homeotic gene APETALA1. Nature 360: 273-277.

Meyerowitz, E.M., D.R. Smyth, and J.L. Bowman. 1989. Abnormal flowers and pattern formation in floral development. Development 106: 209-217.

Meyerowitz, E.M., J.L. Bowman, L.L. Brockman, G.N. Drews, T. Jack, L.E. Sieburth, and D. Weigel. 1991. A genetic and molecular model for flower development in Arabidopsis thaliana. Development (Suppl.) 1: 157-167.

Mizukami, Y. and H. Ma. 1992. Ectopic expression of the floral homeotic gene AGAMOUS in transgenic Arabidopsis plants alters floral organ identity. Cell 71: 119-131.

Mueller, C.G. and A. Nordheim. 1991. A protein domain conserved between yeast MCM1 and human SRF directs ternary complex formation. EMBO I. 10: 4219-4229.

Norman, C., M. Runswick, R. Pollock, and R. Treisman. 1988. Isolation and properties of cDNA clones encoding SRF, a transcription factor that binds to the c-fos serum response element. Cell 55: 989-1003.

Okamuro, J.K., B.G.W. den Boer, and K.D. Jofuku. 1993. Regulation of Arabidopsis flower development. Plant Cell 5: 1183-1193.

Passmore, S., G.T. Maine, R. Elble, C. Christ, and B.K. Tye. 1988. A Saccharomyces cerevisiae protein involved in plasmid maintenance is necessary for mating of MAT $\alpha$ cells. $J$ 
Mol. Biol. 204: 593-606.

Pnueli, L., M. Abu-Abeid, D. Zamir, W. Nacken, Z. SchwarzSommer, and E. Lifschitz. 1991. The MADS box gene family in tomato: Temporal expression during floral development, conserved secondary structures and homology with homeotic genes from Antirrhinum and Arabidopsis. Plant $J$. 1: 255-266.

Pollock, R. and R. Treisman. 1990. A sensitive method for the determination of protein-DNA binding specificities. Nucleic Acids Res. 18: 6197-6204.

Putterill, J., F. Robson, K. Lee, and G. Coupland. 1993. Chromosome walking with YAC clones in Arabidopsis: Isolation of $1700 \mathrm{~kb}$ of contiguous DNA on chromosome 5, including a $300 \mathrm{~kb}$ region containing the flowering-time gene CO. Mol. Gen. Genet. 239: 145-157.

Roe, J.L., C.J. Rivin, R.A. Sessions, K.A. Feldmann, and P.C. Zambryski. 1993. The Tousled gene in A. thaliana encodes a protein kinase homolog that is required for leaf and flower development. Cell 75: 939-950.

Schmidt, R.J., B. Veit, M.A. Mandel, M. Mena, S. Hake, and M.F. Yanofsky. 1993. Identification and molecular characterization of $Z A G 1$, the maize homologue of the Arabidopsis floral homeotic gene, AGAMOUS. Plant Cell 5: 729-737.

Schultz, E.A. and G.W. Haughn. 1991. LEAFY, a homeotic gene that regulates inflorescence development in Arabidopsis. Plant Cell 3: 771-781.

- 1993. Genetic analysis of the floral initiation process (FLIP) in Arabidopsis. Development 119: 745-765.

Schultz, E.A., F.B. Pickett, and G.W. Haughn. 1991. The FLO10 gene product regulates the expression domain of homeotic genes $A P 3$ and $P I$ in Arabidopsis flowers. Plant Cell 3: 12211237.

Schwarz-Sommer, Z., P. Huijser, W. Nacken, H. Saedler, and H. Sommer. 1990. Genetic control of flower development: Homeotic genes in Antirrhinum majus. Science 250: 931-936.

Schwarz-Sommer, Z., I. Hue, P. Huijser, P.J. Flor, R. Hansen, F. Tetens, W.-E. Lönnig, H. Saedler, and H. Sommer. 1992. Characterization of the Antirrhinum homeotic MADS-box gene deficiens: Evidence for DNA binding and autoregulation of its persistent expression throughout flower development. EMBO I. 11: 251-263.

Shannon, S. and D.R. Meeks-Wagner. 1991. A mutation in the Arabidopsis TFL1 gene affects inflorescence meristem development. Plant Cell 3: 877-892.

-1993. Genetic interactions that regulate inflorescence development in Arabidopsis. Plant Cell 5: 639-655.

Shiraishi, H., K. Okada, and Y. Shimura. 1993. Nucleotide sequences recognized by the AGAMOUS MADS domain of Arabidopsis thaliana in vitro. Plant J. 4: 385-398.

Smyth, D.R., J.L. Bowman, and E.M. Meyerowitz. 1990. Early flower development in Arabidopsis. Plant Cell 2: 755-767.

Sommer, H., J.-P. Beltran, P. Huijser, H. Pape, W.-E. Lonnig, H. Saedler, and Z. Schwarz-Sommer. 1990. Deficiens, a homeotic gene involved in the control of flower morphogenesis in Antirrhinum majus: The protein shows homology to transcription factors. $E M B O I$. 9: 605-613.

Sung, Z.R., A. Belachew, B. Shunong, and R. Bertrand-Garcia. 1992. EMF, an Arabidopsis gene required for vegetative shoot development. Science 258: 1645-1647.

Tröbner, W., L. Ramirez, P. Motte, I. Hue, P. Huijser, W.-E. Lönnig, H. Saedler, H. Sommer, and Z. Schwarz-Sommer. 1992. GLOBOSA: A homeotic gene which interacts with $D E F I C I E N S$ in the control of Antirrhinum floral organogenesis. EMBO I. 11: 4693-4704.

Tsuchimoto, S., A.R. van der Krol, and N.-H. Chua. 1993. Ectopic expression of pMADS 3 in transgenic petunia pheno- copies the petunia blind mutant. Plant Cell 5: 843-853.

van der Krol, A.R., A. Brunelle, S. Tsuchimoto, and N.-H. Chua. 1993. Functional analysis of petunia floral homeotic MADS box gene pMADS1. Genes \& Dev. 7: 1214-1228.

Weigel, D., J. Alvarez, D.R. Smyth, M.F. Yanofsky, and E.M. Meyerowitz. 1992. LEAFY controls floral meristem identity in Arabidopsis. Cell 69: 843-59.

Weigel, D. and E.M. Meyerowitz. 1993a. Activation of floral homeotic genes in Arabidopsis. Science 261: 1723-1726.

- 1993b. Genetic hierarchy controlling flower development. In Molecular basis of morphogenesis led. M. Bernfield), pp. 91-105. Wiley-Liss, New York.

- 1993c. LEAFY controls meristem identity in Arabidopsis. In Cellular communication in plant (ed. R. Amasino), pp. 115-122. Plenum, New York.

Wynne, J. and R. Treisman. 1992. SRF and MCM1 have related but distinct DNA binding specificities. Nucleic Acids Res. 20: 3297-3303.

Yanofsky, M.F., H. Ma, J.L. Bowman, G.N. Drews, K.A. Feldmann, and E.M. Meyerowitz. 1990. The protein encoded by the Arabidopsis homeotic gene agamous resembles transcription factors. Nature 346: 35-39. 


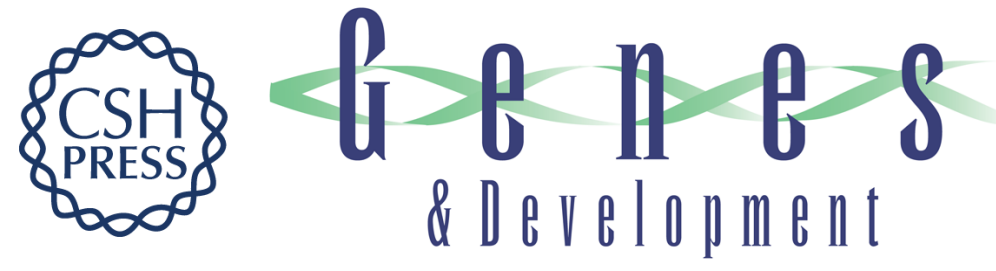

\section{The unfolding drama of flower development: recent results from genetic and molecular analyses.}

$\mathrm{H} \mathrm{Ma}$

Genes Dev. 1994, 8:

Access the most recent version at doi:10.1101/gad.8.7.745

References This article cites 68 articles, 30 of which can be accessed free at:

http://genesdev.cshlp.org/content/8/7/745.full.html\#ref-list-1

License

Email Alerting

Service

Receive free email alerts when new articles cite this article - sign up in the box at the top right corner of the article or click here.

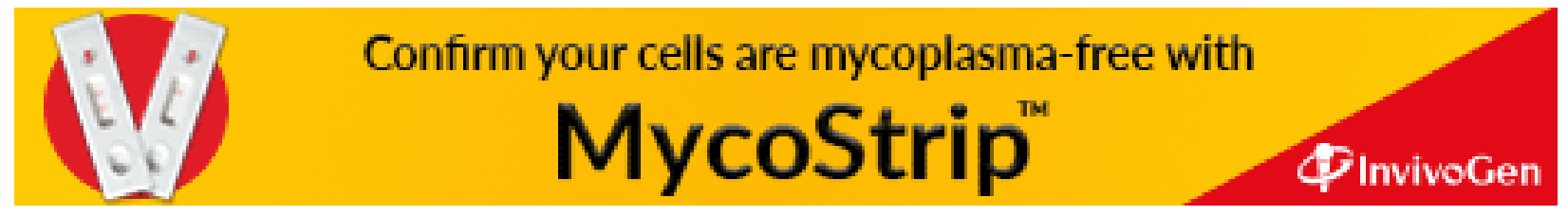

